\title{
Noninvasive Near-Infrared Fluorescence Imaging of the Ureter During Robotic Surgery: A Demonstration in a Porcine Model
}

Citation for published version (APA):

Al-Taher, M., Okamoto, N., Felli, E., Agnus, V., Barberio, M., Gioux, S., Bouvy, N., Stassen, L.,

Marescaux, J., \& Diana, M. (2020). Noninvasive Near-Infrared Fluorescence Imaging of the Ureter During Robotic Surgery: A Demonstration in a Porcine Model. Journal of Laparoendoscopic \& Advanced Surgical Techniques, 30(9), 962-966. https://doi.org/10.1089/lap.2020.0399

Document status and date:

Published: 01/09/2020

DOI:

10.1089/lap.2020.0399

Document Version:

Publisher's PDF, also known as Version of record

\section{Document license:}

Taverne

Please check the document version of this publication:

- A submitted manuscript is the version of the article upon submission and before peer-review. There can be important differences between the submitted version and the official published version of record.

People interested in the research are advised to contact the author for the final version of the publication, or visit the DOI to the publisher's website.

- The final author version and the galley proof are versions of the publication after peer review.

- The final published version features the final layout of the paper including the volume, issue and page numbers.

Link to publication

\footnotetext{
General rights rights.

- You may freely distribute the URL identifying the publication in the public portal. please follow below link for the End User Agreement:

www.umlib.nl/taverne-license

Take down policy

If you believe that this document breaches copyright please contact us at:

repository@maastrichtuniversity.nl

providing details and we will investigate your claim.
}

Copyright and moral rights for the publications made accessible in the public portal are retained by the authors and/or other copyright owners and it is a condition of accessing publications that users recognise and abide by the legal requirements associated with these

- Users may download and print one copy of any publication from the public portal for the purpose of private study or research.

- You may not further distribute the material or use it for any profit-making activity or commercial gain

If the publication is distributed under the terms of Article $25 \mathrm{fa}$ of the Dutch Copyright Act, indicated by the "Taverne" license above, 


\title{
Noninvasive Near-Infrared Fluorescence Imaging of the Ureter During Robotic Surgery: A Demonstration in a Porcine Model
}

\author{
Mahdi Al-Taher, MD, ${ }^{1,2}$ Nariaki Okamoto, MD, ${ }^{3}$ Eric Felli, Msc, ${ }^{1}$ Vincent Agnus, $\mathrm{PhD},{ }^{1}$ \\ Manuel Barberio, MD, PhD, ${ }^{1}$ Sylvain Gioux, PhD, ${ }^{1,4}$ Nicole Bouvy, MD, PhD, ${ }^{2}$ Laurents Stassen, MD, PhD, ${ }^{2}$ \\ Jacques Marescaux, MD, FACS, (Hon) FRCS, (Hon) FJSES, (Hon) FASA, ${ }^{3}$ and Michele Diana, MD, PhD ${ }^{1,3,4}$
}

\begin{abstract}
Background: Iatrogenic ureteral injury is one of the feared complications during intrapelvic surgery. There are limited data on the use of novel near-infrared fluorescence (NIRF) imaging dyes for the purpose of noninvasive ureteral visualization in robot-assisted laparoscopic surgery (RALS). In this study, we evaluated the feasibility of NIRF imaging of the ureter using the IRDye ${ }^{\circledR} 800 \mathrm{BK}$ dye as the fluorescence dye and a robotic platform with Firefly ${ }^{\mathrm{TM}}$ technology as an imaging system.

Materials and Methods: An intravenous dose of $0.15 \mathrm{mg} / \mathrm{kg}$ was administered in 3 pigs and NIRF imaging was performed for a total duration of 60 minutes. The intraoperative video recordings were analyzed to determine fluorescence intensities and the target-to-background ratio (TBR).

Results: In all included animals, a clear delineation of the ureter was achieved from 5 minutes after dye administration until the end of the study. During this time period, the ureter was clearly distinguishable from its surroundings and no statistical differences in TBR were observed.

Conclusion: The IRDye 800BK dye, a novel NIRF dye currently undergoing clinical translation, is a promising contrast agent used for noninvasive ureteral imaging, which has the potential to be valuable during RALS.
\end{abstract}

Keywords: near-infrared fluorescence imaging, ureter, robotic surgery, IRDye800BK, nerindocianine sodium

\section{Introduction}

$\mathbf{R}$ OBOTIC SURGERY HAS been extensively used in various types of surgery, including intrapelvic surgery for urological, gynecologic, and colorectal diseases, and the cases performed globally have rapidly increased for the past decade. ${ }^{1}$ The benefits of robotic surgery include immersive three-dimensional viewing, improved ergonomics, tremor filtration and motion scaling, instrument articulation, and enhanced dexterity with a stable endoscopic platform. ${ }^{2}$ These advantages allow for an accurate approach even in a narrow pelvic cavity. However, as for intraoperative complications in rectal cancer surgery, the first multicenter randomized controlled trial comparing robot-assisted laparoscopic surgery (RALS) with conventional laparoscopic surgery (CLS) for rectal cancer reported no significant difference between RALS and CLS. ${ }^{3}$ During RALS, the surgeon lacks tactile sensation and as a result, the surgeon must primarily rely on visual cues. ${ }^{4,5}$

Ureteral injury is a complication of concern during intrapelvic surgery and the majority of iatrogenic ureteral injuries are not recognized intraoperatively, which may lead to severe morbidity and even mortality. ${ }^{6,7}$ In gynecologic surgery, even when performed in robotic surgery, ureteral injuries occur in $0.3 \%$ to $2.5 \%$ of patients undergoing hysterectomy. ${ }^{8,9}$

\footnotetext{
${ }^{1}$ Institute of Image-Guided Surgery, IHU Strasbourg, Strasbourg, France.

${ }^{2}$ Department of Surgery, Maastricht University Medical Center, Maastricht, The Netherlands.

${ }^{3}$ Research Institute against Digestive Cancer, IRCAD, Strasbourg, France.

${ }^{4}$ ICUBE Laboratory, Photonics Instrumentation for Health, Strasbourg, France.
} 
Near-infrared fluorescence (NIRF) imaging with preoperative optical dye administration may improve the safety and efficiency of intrapelvic surgery by visualizing the ureter. There are several studies describing various fluorescent dyes used to identify the ureters during surgery. ${ }^{10}$ Indocyanine green (ICG), which is approved for clinical use, is considered a potent NIR fluorophore. However, it is metabolized by the liver and exclusively excreted in bile, and as such, it does not facilitate the noninvasive visualization of the ureters. ${ }^{11}$ Several studies described intraurethral ICG injection, which enhanced the intraoperative ureteral NIR visualization during RALS. ${ }^{12-14}$

Methylene blue is another clinically available dye, which was found feasible for ureteral NIR visualization in clinical trials ${ }^{15-17}$ but did not prove its superiority over conventional white light imaging in all cases studied.

A preclinical NIR fluorophore, the IRDye ${ }^{\circledR} 800 \mathrm{CW}$ dye, is a fluorophore that is partly excreted in urine, which allows for noninvasive NIR ureteral visualization. ${ }^{18-20}$ It has an absorption and emission spectrum that overlaps with ICG, and it is consequently compatible with existing NIR imaging systems that have been studied in combination with ICG. Tanaka et al. ${ }^{18}$ and Schols et al. ${ }^{19}$ first reported the use of NIRF imaging with intravenous (IV) injection of IRDye $800 \mathrm{CW}$ for the successful visualization of the ureter in an animal model. IRDye 800BK (nerindocianine sodium) is a cheaper derivative of IRDye $800 \mathrm{CW}$ especially designed for ureteral imaging, which has resulted in the successful NIR visualization of the ureters ${ }^{21}$ and is currently under evaluation for clinical translation in clinical trials (NCT03106038 and NCT03387410).

To date, unlike in laparoscopic surgery, there are limited data on the use of novel dyes in RALS for the purpose of noninvasive ureteral visualization. In this study, we evaluated the feasibility of NIRF imaging of the ureter using IRDye $800 \mathrm{BK}$ as the fluorescence dye and a robotic platform with Firefly $^{\mathrm{TM}}$ technology as an imaging system.

\section{Materials and Methods}

The study was performed at the Research Institute against Digestive Cancer (IRCAD, France). Three female pigs (Sus scrofa domesticus, ssp. Large White) with a weight range comprised between 27 and $35 \mathrm{~kg}$ (mean: $30 \mathrm{~kg}$ ) were included and managed according to the French regulations for animal use and care and to the ARRIVE guidelines. ${ }^{22}$ For ethical purposes, respecting the " $3 \mathrm{R}$ 's" (Replace, Refine, Reduce) principles of animal research, ${ }^{23}$ we performed this study in pigs, which were used for educational purposes for novel robotic surgeons without imposing any urological or pelvic organ damage (ethical protocol number 38.2019.01.124). Premedication consisted of zolazepam and tiletamine $10 \mathrm{mg} / \mathrm{kg}$ intramuscular (IM) (Zoletil ND, Virbac, France), and anesthesia was induced using an IV injection of propofol $3 \mathrm{mg} / \mathrm{kg}$ (Propofol Lipuro ND, B Braun, France) and rocuronium $0.8 \mathrm{mg} / \mathrm{kg}$ (Esmeron ND, MSD, France), allowing for intubation and mechanical ventilation. Sedation was maintained by means of an inhalation of isoflurane $2 \%$ to $3 \%$ (Isoflurin ND, Axience, France) and oxygen. Buprenorphine (Buprecare $\mathrm{ND}$, Axience, France) $0.01 \mathrm{mg} / \mathrm{kg}$ IM was used for analgesia. At the end of the surgical procedure, pigs were sacrificed under deep anesthesia (isoflurane 5\%) with IV injection of pentobarbital $40 \mathrm{mg} / \mathrm{kg}$ (Exagon ND, Axience, France).

\section{Preparation of the dyes}

IRDye 800BK powder was diluted in a sterile phosphatebuffered saline solution to a concentration of $1 \mathrm{mg} / \mathrm{mL}$ and was injected intravenously at a concentration of $0.15 \mathrm{mg} / \mathrm{kg}$ body weight.

\section{Robotic surgical system}

The da Vinci ${ }^{\circledR}$ Si surgical system (Intuitive Surgical, Inc.) with Firefly technology was used. All procedures were digitally recorded with the built-in recording equipment for postoperative analysis.

\section{Surgical procedure}

The pigs were placed in a prone position and secured to the operating table. Four trocars were inserted under laparoscopic guidance and the arms of the da Vinci Si robot were docked accordingly. NIRF imaging was recorded continuously for a duration of 60 minutes after IV dye administration. The ureter was defined as "identified" with certainty when a clear peristaltic contraction of the ureter with transport of urine toward the bladder was visualized under NIRF.

\section{Analysis}

The NIRF video recordings were analyzed after selecting representative screenshots of the ureter after 5, 20, 40, and 60 minutes of dye administration, respectively.

With the GNU Image Manipulation Program (the GIMP team, GIMP 2.8.10), the target (ureter) and the background (peritoneum $1 \mathrm{~cm}$ lateral to the ureter) were highlighted and corresponding fluorescence intensities (FI) from these regions of interest were measured with the SciPy Python data science module. Finally, fluorescence images were analyzed by determining the target-to-background ratio (TBR), which is defined as the mean FI of the target minus the mean FI of the background divided by the mean FI of the background, and corresponding graphs were made using the GraphPad 8.3 software. One-way analysis of variance (ANOVA) with Tukey's multiple comparisons test and two-way ANOVA with Sidak's multiple comparison tests were performed to calculate differences in continuous variables. A two-tailed analysis with a $P$ value $<.05$ was considered statistically significant.

\section{Results}

In all 3 animals included, it was possible to clearly visualize the ureters under NIRF imaging from 5 minutes after dye administration until the end of the surgical procedure (Fig. 1). Subjectively, the ureter became more distinguishable from its surroundings and reached its peak around 20 minutes after which the ureter remained clearly visible during peristaltic contractions until the end of the procedure. There was a positive TBR at all time points measured and there was no statistical difference of the TBR value over time (Table 1 and Fig. 2). 


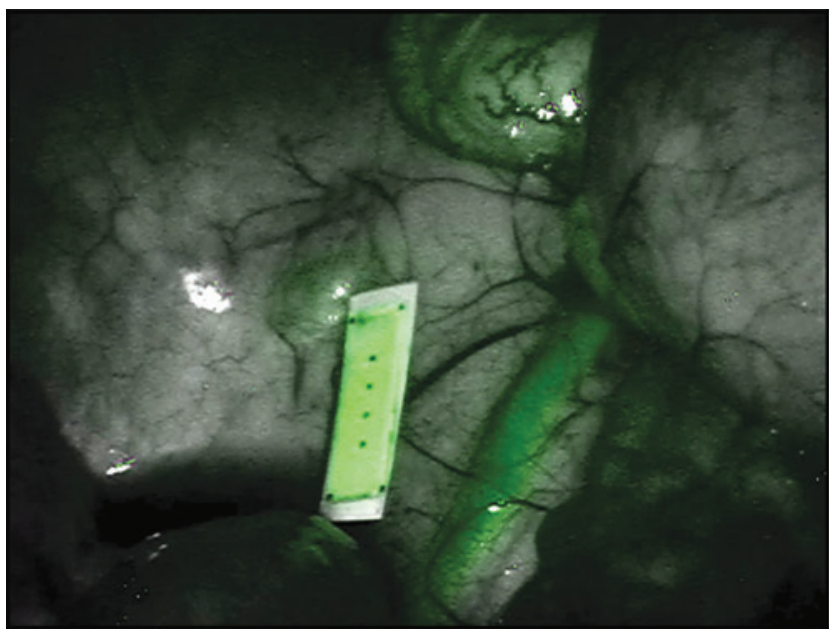

FIG. 1. Screenshot of the left ureter after 20 minutes of dye administration.

Another valuable finding observed in all included animals was the clear visualization of bowel perfusion directly after dye administration as shown in Figure 3.

No complications related to dye administrations occurred.

\section{Discussion}

In this study, we have successfully demonstrated the feasibility of NIRF ureteral identification with IRDye 800BK and the commercially available Firefly technology of the da Vinci Si robotic surgical system in a pig model. This is an essential finding adding a new potent fluorophore, currently undergoing clinical translation, to the armamentarium of robotic surgery. Unlike in CLS, only a limited number of clinical and preclinical fluorophores have been successfully explored for ureteral imaging with the da Vinci robotic surgical systems. ${ }^{24,25}$

To prevent intraoperative ureteral injury, surgeons have made an effort to visualize the ureter using various methods,

Table 1. Summary of Study Characteristics AND RESULTS

Pig number (total body weight, dye concentration, total amount of dye administered)

Time

$1(35 \mathrm{~kg}, 0.15 \mathrm{mg} / \mathrm{kg}, 5.25 \mathrm{mg})$ (minutes) $T B R$

$2(28 \mathrm{~kg}, 0.15 \mathrm{mg} / \mathrm{kg}, 4.20 \mathrm{mg})$

$3(27 \mathrm{~kg}, 0.15 \mathrm{mg} / \mathrm{kg}, 4.05 \mathrm{mg})$

$5^{\mathrm{a}}$

0.81

40

0.71

1.31

60

0.83

$5^{a}$

60

0.39

0.41

0.92

1.54

0.61

0.65

1.98

2.13

${ }^{\mathrm{a}}$ First certain ureteral visualization under near-infrared fluorescence imaging.

TBR, target-to-background ratio.

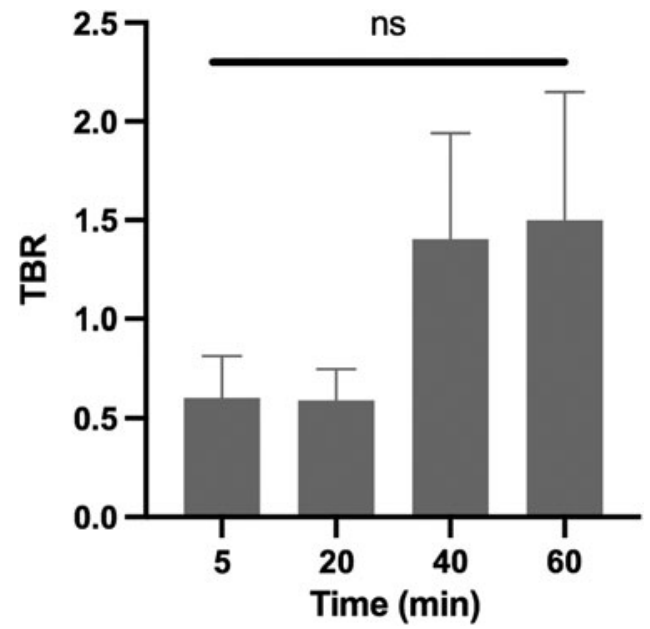

FIG. 2. The TBR over time, showing no significant difference between measured time points. ns, no statistical significance; TBR, target-to-background ratio.

including preoperative ureteral stent insertion, ${ }^{26-28}$ lighted ureteral stents, ${ }^{29}$ intraoperative cystoscopy, ${ }^{8,30,31} \mathrm{X}$-ray fluoroscopy, ${ }^{32}$ and intraureteral ICG injection. ${ }^{11,12,14}$ These procedures require additional interventions, which can be both time-consuming and add extra costs to the surgical procedure and they may also introduce an additional risk of complications.

Although ICG is the most commonly used fluorophore for intraoperative fluorescence imaging, it remains suboptimal for ureteral imaging due to its exclusive hepatic clearance, which prevents it to reach the ureter noninvasively. It, therefore, requires an invasive procedure such as a cystoscopy with ureteral cannulation to reach the ureter. This necessitates the introduction of other more potent fluorophores for ureteral imaging. In a first-in-human experience in patients undergoing robotic hysterectomy, Farnam et al. ${ }^{25}$ demonstrated that the use of NIRF imaging is feasible with IV injection of IS-001, a hydrophilic dye with a maximum

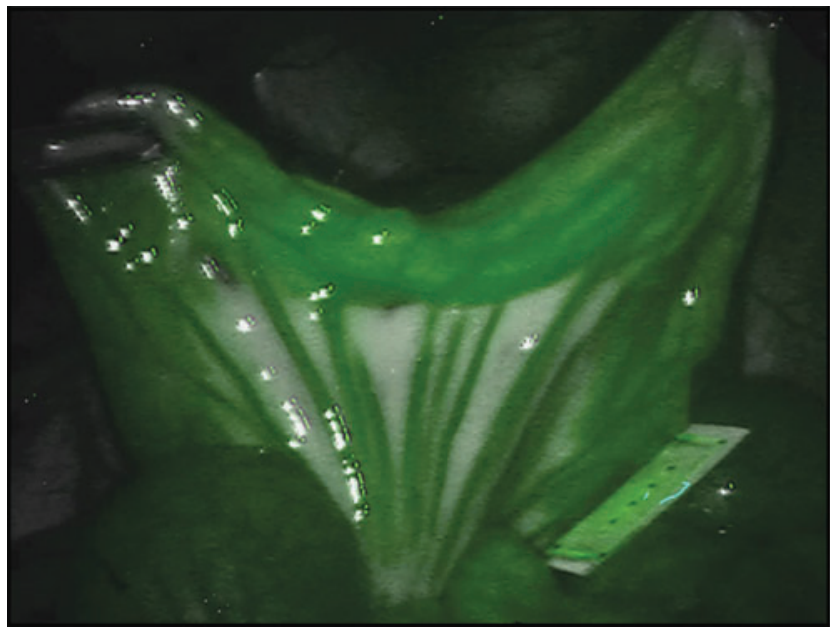

FIG. 3. Screenshot of an intestinal loop within 1 minute of intravenous dye administration showing a clear intestinal perfusion under NIRF. NIRF, near-infrared fluorescence. 


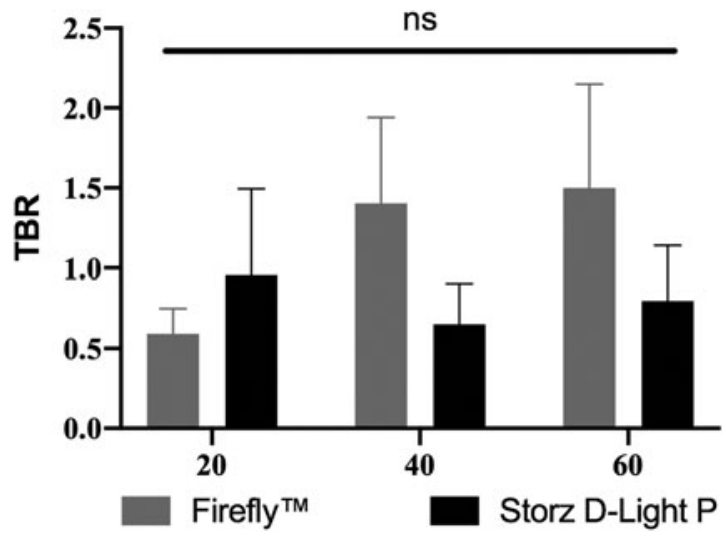

FIG. 4. The TBR over time, showing no significant difference between measured time points between the Firefly ${ }^{\mathrm{TM}}$ technology and the KARL STORZ D-Light P NIR laparoscope.

absorption at $790 \mathrm{~nm}$ and a maximum emission at $815 \mathrm{~nm}$, for the intraoperative visualization of the ureter. Another promising fluorophore for enhanced ureteral visualization is ZW-800-1, which has been explored in the clinical setting. ${ }^{24}$

The feasibility of IRDye 800BK for the intraoperative visualization of the ureter has been previously demonstrated in laparoscopic surgery in preclinical trials by our group..$^{21,33}$

This dye is mainly cleared by the kidney, making it suitable for noninvasive intraoperative ureteral imaging. However, it is also partially cleared by the liver resulting in the potential of NIRF bile duct imaging as we have demonstrated earlier. ${ }^{33}$ In addition, in yet unpublished data, we successfully demonstrated that it was possible to simultaneously visualize the ureter, bile duct, bowel perfusion, lymph ducts, and lymph nodes in the same surgical procedure.

Considering the speed of ureteral visualization under NIRF, which occurred as soon as 5 minutes after dye administration, it is clear that the dye can be administered intraoperatively without the need for an extension of the duration of the operative procedure as is the case when compared with ureteral stent insertion or intraureteral dye administration, which is usually performed before the start of the surgical procedure.

To compare the results of this study, we have retrieved historical data from our previous studies with NIRF imaging of the ureter with an NIR laparoscope (D-Light-P; KARL STORZ, Germany). In 5 animals, a similar concentration of $0.15 \mathrm{mg} / \mathrm{kg}$ was administered and representative screenshots of the video recordings were made after 20,40, and 60 minutes of dye administration. By using the same method of TBR calculation as explained in this study, we found TBR values that were not significantly different from our current findings (Fig. 4). This suggests that this dye has an equally good performance for ureteral visualization in both systems. However, it is uncertain if these findings are all translatable to the clinical setting. Since visceral fat in pigs is thinner and the ureteral diameter is smaller than in humans, ${ }^{33}$ studies will be necessary to confirm the applicability of this dye in the clinical setting.

Although this study describes a small sample size, being a feasibility study aiming to serve as a proof of principle, only 3 pigs were deemed sufficient to demonstrate the feasibility of intraoperative real-time ureteral imaging in combination with the robotic system. A disadvantage lies in the fact that the total duration of the surgical procedure was only 1 hour due to logistic reasons. However, in our earlier studies, we have demonstrated that it was possible to visualize the ureters until at least 120 minutes after administration of a single bolus of this dye. 21,33

Although this study was performed in pigs that underwent several surgical procedures, presenting possible hemodynamic alterations, it was still possible to visualize the ureters in all cases.

In this study, only one dye concentration $(0.15 \mathrm{mg} / \mathrm{kg})$ was explored. In earlier studies, other doses were successfully explored in laparoscopic surgery, suggesting that there is a range of dye concentrations that results in successful ureteral visualization and that further studies are required to identify the most ideal concentration for the clinical setting.

Since this dye is currently undergoing clinical translation, a clinical pilot study exploring the feasibility of this fluorophore in RALS and CLS would be the next step to demonstrate its clinical value for NIRF imaging.

\section{Conclusion}

In this study, we successfully demonstrated the feasibility of the noninvasive intraoperative ureteral visualization of the ureter in robotic surgery using the Firefly technology and the NIRF dye IRDye 800BK. This dye, which is currently undergoing clinical translation, is a potent and versatile dye, which adds to the still limited amount of fluorescence dyes explored in robotic surgery.

\section{Acknowledgment}

The authors thank Guy Temporal for his valuable help in proofreading this article.

\section{Disclosure Statement}

J.M. is the president of IRCAD, which is partly funded by KARL STORZ and Medtronic. L.S. and M.D. are members of the Scientific Board of Diagnostic Green. M.D. is the recipient of the ELIOS grant. M.A.-T., N.O., M.B., E.F., V.A., S.G., and N.B. have no conflicts of interest or financial ties to disclose.

\section{Funding Information}

This study was funded by the ARC Foundation through the ELIOS (Endoscopic Luminescent Imaging for precision Oncologic Surgery) grant. LI-COR Biosciences (Lincoln, USA) provided the fluorescent dye used in this study.

\section{References}

1. Marcus HJ, Hughes-Hallett A, Payne CJ, Cundy TP, Nandi D, Yang GZ, et al. Trends in the diffusion of robotic surgery: A retrospective observational study. Int J Med Robot 2017;13:e1870.

2. Matsuyama $T$, Kinugasa $Y$, Nakajima $Y$, Kojima $K$. Robotic-assisted surgery for rectal cancer: Current state and future perspective. Ann Gastroenterol Surg 2018;2:406-412.

3. Jayne D, Pigazzi A, Marshall H, Croft J, Corrigan N, Copeland $\mathrm{J}$, et al. Effect of robotic-assisted vs conventional 
laparoscopic surgery on risk of conversion to open laparotomy among patients undergoing resection for rectal cancer: The ROLARR randomized clinical trial. JAMA 2017;318:1569-1580.

4. Hagen ME, Meehan JJ, Inan I, Morel P. Visual clues act as a substitute for haptic feedback in robotic surgery. Surg Endosc 2008;22:1505-1508.

5. Okamura AM. Haptic feedback in robot-assisted minimally invasive surgery. Curr Opin Urol 2009;19:102-107.

6. Mueller MG, Kenton K. Re: Complications of recognized and unrecognized iatrogenic ureteral injury at time of hysterectomy: A population based analysis. J Urol 2019; 202:1054-1055.

7. Marcelissen TA, Den Hollander PP, Tuytten TR, Sosef MN. Incidence of iatrogenic ureteral injury during open and laparoscopic colorectal surgery: A single center experience and review of the literature. Surg Laparosc Endosc Percutan Tech 2016;26:513-515.

8. Teeluckdharry B, Gilmour D, Flowerdew G. Urinary tract injury at benign gynecologic surgery and the role of cystoscopy: A systematic review and meta-analysis. Obstet Gynecol 2015;126:1161-1169.

9. Lee Z, Kaplan J, Giusto L, Eun D. Prevention of iatrogenic ureteral injuries during robotic gynecologic surgery: A review. Am J Obstet Gynecol 2016;214:566-571.

10. Slooter MD, Janssen A, Bemelman WA, Tanis PJ, Hompes R. Currently available and experimental dyes for intraoperative near-infrared fluorescence imaging of the ureters: A systematic review. Tech Coloproctol 2019;23: 305-313.

11. Kanabur P, Chai C, Taylor J. Use of indocyanine green for intraoperative ureteral identification in nonurologic surgery. JAMA Surg 2020 [Epub ahead of print]; DOI: 10.1001/jamasurg.2020.0094.

12. Lee Z, Simhan J, Parker DC, Reilly C, Llukani E, Lee DI, et al. Novel use of indocyanine green for intraoperative, real-time localization of ureteral stenosis during robotassisted ureteroureterostomy. Urology 2013;82:729-733.

13. Pathak RA, Hemal AK. Intraoperative ICG-fluorescence imaging for robotic-assisted urologic surgery: Current status and review of literature. Int Urol Nephrol 2019;51:765771.

14. Lee Z, Moore B, Giusto L, Eun DD. Use of indocyanine green during robot-assisted ureteral reconstructions. Eur Urol 2015;67:291-298.

15. Al-Taher M, van den Bos J, Schols RM, Bouvy ND, Stassen LP. Fluorescence ureteral visualization in human laparoscopic colorectal surgery using methylene blue. J Laparoendosc Adv Surg Tech A 2016;26:870-875.

16. Barnes TG, Hompes R, Birks J, Mortensen NJ, Jones O, Lindsey I, et al. Methylene blue fluorescence of the ureter during colorectal surgery. Surg Endosc 2018;32:40364043.

17. Verbeek FP, van der Vorst JR, Schaafsma BE, Swijnenburg $\mathrm{RJ}$, Gaarenstroom KN, Elzevier HW, et al. Intraoperative near infrared fluorescence guided identification of the ureters using low dose methylene blue: A first in human experience. J Urol 2013;190:574-579.

18. Tanaka E, Ohnishi S, Laurence RG, Choi HS, Humblet V, Frangioni JV. Real-time intraoperative ureteral guidance using invisible near-infrared fluorescence. J Urol 2007;178: 2197-2202.

19. Schols RM, Lodewick TM, Bouvy ND, van Dam GM, Dejong $\mathrm{CH}$, Stassen LP. Application of a new dye for near-infrared fluorescence laparoscopy of the ureters: Demonstration in a pig model. Dis Colon Rectum 2014; 57:407-411.

20. Korb ML, Huh WK, Boone JD, Warram JM, Chung TK, de Boer E, et al. Laparoscopic fluorescent visualization of the ureter with intravenous IRDye800CW. J Minim Invasive Gynecol 2015;22:799-806.

21. van den Bos J, Al-Taher M, Bouvy ND, Stassen LPS. Nearinfrared fluorescence laparoscopy of the ureter with three preclinical dyes in a pig model. Surg Endosc 2019;33:986991.

22. Group NCRRGW. Animal research: Reporting in vivo experiments: The ARRIVE guidelines. J Physiol 2010; 588(Pt 14):2519-2521.

23. Kirk RGW. Recovering the principles of humane experimental technique: The $3 \mathrm{Rs}$ and the human essence of animal research. Sci Technol Human Values 2018;43:622648.

24. de Valk KS, Handgraaf HJ, Deken MM, Sibinga Mulder BG, Valentijn AR, Terwisscha van Scheltinga AG, et al. A zwitterionic near-infrared fluorophore for real-time ureter identification during laparoscopic abdominopelvic surgery. Nat Commun 2019;10:3118.

25. Farnam RW, Arms RG, Klaassen AH, Sorger JM. Intraoperative ureter visualization using a near-infrared imaging agent. J Biomed Opt 2019;24:1-8.

26. Tanaka Y, Asada H, Kuji N, Yoshimura Y. Ureteral catheter placement for prevention of ureteral injury during laparoscopic hysterectomy. J Obstet Gynaecol Res 2008; 34:67-72.

27. Wood EC, Maher P, Pelosi MA. Routine use of ureteric catheters at laparoscopic hysterectomy may cause unnecessary complications. J Am Assoc Gynecol Laparosc 1996; 3:393-397.

28. Redan JA, McCarus SD. Protect the ureters. JSLS 2009;13: 139-141.

29. Siddighi S, Carr KR. Lighted stents facilitate roboticassisted laparoscopic ureterovaginal fistula repair. Int Urogynecol J 2013;24:515-517.

30. Sandberg EM, Cohen SL, Hurwitz S, Einarsson JI. Utility of cystoscopy during hysterectomy. Obstet Gynecol 2012; 120:1363-1370.

31. Worldwide AAMIG. AAGL practice report: Practice guidelines for intraoperative cystoscopy in laparoscopic hysterectomy. J Minim Invasive Gynecol 2012;19:407411.

32. Park S, Pearle MS. Imaging for percutaneous renal access and management of renal calculi. Urol Clin North Am 2006;33:353-364.

33. Al-Taher M, van den Bos J, Schols RM, Kubat B, Bouvy ND, Stassen LPS. Evaluation of a novel dye for nearinfrared fluorescence delineation of the ureters during laparoscopy. BJS Open 2018;2:254-261.

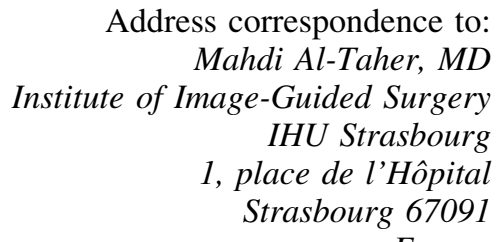

France

E-mail: mahdi.al-taher@ihu-strasbourg.eu 